\title{
A utopia de uma sociedade sem raças
}

Peter FRY. A persistência da raça: ensaios antropológicos sobre o Brasil e a África Austral. Rio de Janeiro, Civilização Brasileira, 2005. 348 páginas.

\section{Márcio Macedo}

Peter Fry é um antropólogo que dispensa apresentação no campo da antropologia brasileira. Seu último trabalho, A persistência da raça: ensaios antropológicos sobre o Brasil e a África Austral, pode ser classificado, para além de sua importância científica, como um grande manifesto anti-raça em países de colonização ibérica do hemisfério sul. O livro como um todo é resultado da reunião de artigos, resenhas e ensaios publicados entre 1995 e 2005, focados na discussão sobre o conceito de raça e sua relação com o racismo, racialismo, identidade negra, desigualdades e nacionalidade em diferentes contextos políticos, sociais e geográficos. Composta de onze capítulos mais introdução e conclusão, a obra é dividida em duas partes; a primeira dedicada a países da África Austral, a segunda, ao Brasil.

O fio que conduz todos os textos é o posicionamento anti-raça do autor que se contrapõe "à ortodoxia dos movimentos negros e de grande parte da academia" (p. 17). Para Fry, "quando a crença generalizada em raças adquire a força da lei, ela se torna cada vez mais difícil de erradicar" (p. 15). A partir dessa constatação, o autor argumenta em favor de políticas públicas universalistas, que não reelaboram ou reificam a noção de raça, contrapondo-se a políticas públicas diferencialistas de tradição anglo-saxão. Com base nesse pressuposto, Fry descreve o processo de racialização via celebração da diversidade racial, que estaria ocorrendo em países como Moçambique e Brasil.

No capítulo de abertura, explora-se o caso de Moçambique diante da política colonial portuguesa de assimilacionismo e de como esta não constituía algo reificado, possuindo pontos de convergência com as políticas segregacionistas da colonização britânica. Nos anos de 1970, o regime socialista de Samora Machel reinterpretou o assimilacionismo português em bases marxistas, crian- 
do o ideal do "homem novo". A guerra civil que ocorreu nas duas décadas seguintes entre a Frente de Libertação Moçambicana (Frelimo) e a Resistência Nacional Moçambicana (Renamo) passa a ser interpretada pela população como um castigo dos ancestrais. Por fim, a realidade de Moçambique hoje, pacificado e recém incorporado no British Commonwealth, é de um país que celebra a diversidade ao valorizar a tradição, os diversos idiomas e os grupos étnicos, mediante a atuação de organizações não-governamentais financiadas por agências internacionais.

O segundo capítulo é uma resenha do livro do historiador Terence Ranger, Voices from the rocks: nature, culture \& history in the Matopos Hills of Zimbabwe (1999). Fry conta parte da história da Rodésia, atual Zimbábue, por meio das figuras do colonizador britânico Cecil John Rodes (1853-1902) e do rei Mzilizaki, ambos enterrados na região dos Morros Matopos. Nas palavras do autor, "Voices from the rocks é a história da disputa pelo controle da terra e do poder entre indivíduos e grupos, e dos idiomas, no sentido mais amplo, nos quais a estas disputas seriam (e são) conduzidas. Um dos mais importantes destes idiomas envolve, no Zimbábue como em outros lugares da África, o poder dos mortos em relação aos vivos" (p. 103).

Aproveitando o gancho deixado pelo livro de Ranger, no capítulo três Fry explicita como se dá a relação entre vivos e mortos em Moçambique. Ao recuperar um fato já demonstrado no primeiro capítulo, o autor afirma que parte da população moçambicana tende a encarar as aflições vividas no presente como castigos de ações realizadas por seus ancestrais no passado. Seguindo as pistas fornecidas por uma etnografia de um ritual religioso e de conversas com um pastor, o autor consegue identificar a reposição de uma hierarquia racial, em que parte dos moçambicanos associa os negros à tradição, à feitiçaria e à inferioridade, enquanto os brancos são associados à civilização, ao Espírito Santo e à superioridade. De acordo com Fry, um dos grandes problemas para a extirpação do racismo, tanto na África como em outras partes do mundo, está na tendência de as pessoas encararem os conceitos de "raça" (inconsistente do ponto de vista biológico, mas significativo como um constructo social) e "cultura" como realidades ligadas geneticamente.
A segunda parte do livro tem início com a republicação do texto clássico do autor "Feijoada e soul food". Publicado pela primeira vez nos anos de 1970, esse ensaio foi reelaborado pelo autor anos atrás. Se na primeira versão encontrase um Fry crítico de Gilberto Freyre e da idéia de democracia racial, no texto atual o autor incorpora um posicionamento "neofreyreano", valorizando o conceito anteriormente criticado a partir de uma abordagem estruturalista de mito.

O capítulo seguinte analisa dois livros sobre o Brasil: Orpheus and power, de Michael Hanchard (1994), e Slave rebellion in Brazil, de João José Reis (1995). Crítico em relação ao livro de Hanchard sobre o movimento negro brasileiro e mais simpático à obra de Reis sobre a rebelião malê de 1835 em Salvador (BA), Fry aproveita a comparação para evidenciar no que o Brasil se difere dos Estados Unidos quanto a discussões sobre raça e racismo. Seguindo essa mesma linha argumentativa, no capítulo seguinte o autor responde a um artigo escrito por Hanchard sobre as relações raciais no Brasil. Ele argumenta em favor da maneira múltipla de o país se classificar racialmente e menos racista, segundo ele, do que a tendência bipolar dos Estados Unidos. Ainda em contraposição ao autor afro-americano, que anunciava a morte do mito da democracia racial em seu artigo, o antropólogo reinterpreta tal conceito numa abordagem antropológica estruturalista na qual ela é entendida como uma espécie de ethos brasileiro compartilhado pela população como um todo.

O sétimo capítulo é uma análise acurada das relações entre política, nacionalidade e raça no Brasil. Fry reconstrói a história das relações raciais no país, mostrando os pontos de convergência, divergência e influência do contexto internacional no debate sobre as políticas de raça. O Brasil, segundo ele, tem uma história de mistura racial, hibridismo aliado a uma maneira múltipla de se classificar racialmente, algo que nos últimos trinta anos vem sendo substituído pela classificação racial bipolar, tão ao gosto do movimento negro e de instituições internacionais que estabelecem a diversidade racial e o multiculturalismo como paradigmas de atuação. Fry afirma que essas tendências vão contra a tradição de anti-racialismo do país.

O artigo que se segue é uma interessante incursão etnográfica na publicidade e no mercado 
de cosméticos para entender de que maneira esses meios têm lidado com a idéia de raça. Fugindo das interpretações que entendem a incorporação de modelos negros em anúncios publicitários e a expansão de cosméticos específicos para a população afro-brasileira como demandas de uma classe média emergente, o autor tende a encarar esses fenômenos como produtos/produtores da classe média negra. O marco desse processo seria o surgimento da revista Raça Brasil em 1996. Nas palavras de Fry, "é como se a própria 'aparência' se tornasse (ou esteja se tornando) o ícone da identidade negra no Brasil, levando muita gente que de outra forma se consideraria morena, mulata etc., a considerar-se também "negra'” (p. 254). Seguem-se análises de campanhas publicitárias que utilizam modelos negros e salões de beleza especializados na estética afro, considerados "centros de convivência" para negros, onde se desenvolve "uma sociabilidade que seria um passo significativo na formação de uma identidade coletiva para além de um interesse comum pela "beleza negra" (p. 267). O autor conclui que o "racismo moderno no Brasil como em outros lugares é construído sobre representações negativas associadas a determinadas "aparências" e que "se os fabricantes e propagandistas de beleza [tiverem] o mínimo de sucesso na mudança destas representações (que não são monopolizados pelos membros mais brancos da população) no sentido de transformar em senso comum a noção de que há maneiras de ficar bela(o) e que não há qualquer relação entre aparência e competência, então [...] o tão vilipendiado mercado terá contribuído de forma contundente para a diminuição do racismo no Brasil" (p. 270).

No nono capítulo Fry analisa como a política racial estabelecida no Brasil entre 1995 e 2004 se estendeu para as discussões e formulações das políticas de saúde. O objeto de análise, nesse caso, são as campanhas veiculadas para a disseminação de maiores informações sobre a doença conhecida como anemia falciforme e de como a enfermidade é associada ao corpo negro e, conseqüentemente, à população negra como um todo. Ao historicizar o debate em torno dessa doença nos Estados Unidos a partir dos anos de 1960, Fry mostra como se buscou produzir uma "comunidade negra cidadã e responsável" ao mesmo tempo em que se veiculava informações a respeito da doença. Já no Brasil, esse debate, iniciado nos anos de 1990 com a participação ativa do movimento negro, intencionava não só criar uma "comunidade negra cidadã e responsável", mas também estabelecer uma taxonomia racial bipolar. A partir daí, o autor alerta para os perigos de uma possível estigmatização da anemia falciforme como doença de negros num país com altos índices de miscigenação como o Brasil.

Por fim, no décimo e décimo primeiro capítulo o antropólogo discute a política de cotas estabelecida em algumas universidades brasileiras a partir de 2002. No primeiro, Fry argumenta que o estabelecimento de cotas na Universidade do Estado do Rio de Janeiro (UERJ), com base no projeto de lei apresentado por um deputado estadual desconhecido, foi realizado sem uma discussão pública mais ampla. Para mostrar que existia uma opinião contrária à proposta, o autor selecionou e analisou uma série de cartas enviadas por leitores do jornal $O$ Globo, em que ficam evidentes as razões pelas quais eles eram contra a política de cotas.

No segundo, o autor explora a relação entre raça e classe nas discussões e no estabelecimento da política de cotas no Rio de Janeiro. Fry pretende mostrar, por meio do acompanhamento das mudanças estabelecidas na política de cotas entre 2002 e 2004, como boa parte dos candidatos que votaram a favor dessa política entendia raça como classe, isto é, pobreza e negritude eram termos intercambiáveis. Conclui Fry que as cotas buscam estabelecer uma "cisão racial" no Brasil, dividindo a população entre negros e brancos a partir da exclusão dos mestiços (mulatos) e ressaltando a lógica da classificação racial bipolar, reivindicação do movimento negro. Estabeleceriam, ainda, "uma competição intraclasse entre 'negros' e 'brancos' [...] dos alunos das escolas públicas e/ou das faixas mais pobres da população, onde há uma predominância de negros!" (p. 332).

Em suma, Fry acredita que as ações contra o racismo devem se concentrar na esfera cultural e o combate às desigualdades raciais deve ser realizado por meio de políticas universalistas. Qualquer iniciativa que busque combater essas mesmas desigualdades via enunciação ou consideração da variável "raça" deve ser abortada, pois corrobora 
para a reelaboração do conceito quando, na verdade, o "tiro de misericórdia" no racismo deve ser dado pela desconstrução e, posterior, desuso do conceito. Contudo, descontruir e extinguir o conceito de raça não é algo tão simples de se fazer. Apesar de sua inconsistência do ponto de vista biológico, vários autores, inclusive Fry, mostram a sua existência social. No caso do Brasil, o conceito tem uma posição central na maneira como a idéia de nação foi elaborada e os bens sociais foram e são distribuídos. Ações na esfera cultura, por mais bem intencionadas que sejam, tendem a ter um impacto circunscrito, limitado e demorado sobre desigualdades econômicas com contornos raciais.

Por outro lado, a idéia defendida pelo autor de que a luta e a atuação dos movimentos negros têm se dado no sentido de criar uma "cisão racial" e estabelecer um sistema de classificação racial bipolar também deve ser contextualizada. Por mais que essa tentativa possa existir, a tensão entre os dois tipos de classificação racial (bipolar e múltiplo) é algo constitutivo das relações raciais no Brasil na melhor tradição freyreana de "antagonismos em equilibrio", e, dificilmente, é possível vislumbrar a prevalência de uma das duas. Na verdade, há realidades diferenciadas do ponto de vista geográfico, social, cultural e político num país continental como o nosso que faz com que cada região apresente uma relação de maior ou menor proximidade com cada sistema de classificação racial, o imaginário de mistura racial e a própria noção de raça.

A interpretação que o antropólogo faz da idéia de "democracia racial" como mito com base em uma perspectiva antropológica estruturalista apresenta uma nova maneira de entender esse conceito tão caro à nossa tradição. Contudo, se algumas visões tendem a decretar a morte da "democracia racial" pela atuação dos atores sociais na desconstrução do mito e pela influência do contexto internacional racializado, a análise de Fry não considera a atuação desses mesmos atores devido ao caráter a-histórico das interpretações estruturalistas de mito que tendem a circunscrever a ação dos mitos na esfera do inconsciente dos indivíduos. Além disso, se o autor defende a extirpação da idéia de raça, porque valorizar um conceito que traz à tona justamente essa idéia?

Creio que a análise de Fry é importantíssima e valiosa no sentido de se contrapor às interpreta- ções reducionistas que encaram o sistema de relações raciais do Brasil como uma variação cínica, malfeita e não tão bem-sucedida das relações raciais de tradição anglo-saxão. É preciso que ativistas e formuladores de políticas públicas levem a sério os perigos de uma estigmatização que possa ocorrer em determinadas ações, como exemplifica Fry no caso da anemia falciforme. Contudo, é também necessário que se reflita mais sobre uma injustificável histeria de que ações afirmativas e cotas causem um aumento de tensão racial no país. Políticas focadas não excluem políticas universalistas, e devem ser aplicadas de acordo com as especificidades de cada área. No que diz respeito às discussões sobre raça e racialismo é necessário que ocorra mais diálogo entre ativistas, acadêmicos, políticos, intelectuais e a população como um todo. O Brasil e a África Austral não estão isolados do mundo que, cada vez mais, celebra os ideais da diversidade racial e do multiculturalismo. No caso do Brasil, é necessário que esses termos não sejam vistos como "bichos-papões" de nossa tradição, e que os "neofreyreanos" olhem com mais otimismo para nosso histórico de hibridismo e de lógica antropofágica no sentido de que essa mesma tradição possa reelaborar conceitos globais e criar algo novo. Algo que ainda não conhecemos, pois, como afirma Fry, "as ciências sociais são muito mais confortáveis olhando para o passado que para o futuro!" (p. 34).

\section{MÁRCIO MACEDO é mestre em sociologia pela Universidade de São Paulo (USP).}

